\title{
De Novo Pure Trisomy 20p: Report of a Novel Case of a Marker Chromosome and Literature Review
}

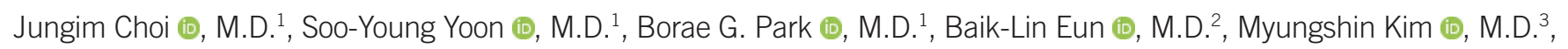
and Jung Ah Kwon $\mathbb{0}$, M.D. ${ }^{1}$

Departments of ${ }^{1}$ Laboratory Medicine and ${ }^{2}$ Pediatrics, Korea University College of Medicine, Seoul, Korea; ${ }^{3}$ Department of Laboratory Medicine, Catholic University College of Medicine, Seoul, Korea

\section{Dear Editor,}

Trisomy 20p is a rare genetic disorder manifesting as intellectual disability, speech delay, specific facial features, and delayed motor milestones. Severity of the symptom depends on chromosome 20p duplication size; larger chromosomal duplications usually result in more serious symptoms [1]. Most previously reported cases involved partial trisomy 20p derived from a parental reciprocal translocation, chromosome inversion, or a small supernumerary marker chromosome (sSMC) [1-5]. However, only a few cases of pure trisomy 20p (involving whole short arm of chromosome 20) have been reported [1, 5-9].

We report a case of pure trisomy 20p arising from a de novo marker chromosome, 20p(47,XX,+mar), with a non-reciprocal translocation, which was characterized at the molecular level by comparative genomic hybridization (CGH). To the best of our knowledge, this is the first case of de novo pure trisomy 20p arising from a marker chromosome in Korea. In addition, we reviewed previously reported cases of trisomy 20p syndrome and compared them with the phenotype of our patient. We received informed consent from the patient for all the genetic testings. This study was approved by the Institution Review Board of Korea University Guro Hospital, Seoul, Korea (IRB-2019GR0429).

The patient was referred at 30 months of age, in June 2017 , to Korea University Guro Hospital, Seoul, Korea, for an evaluation of developmental and speech delay. She was the last of four children of unrelated healthy Korean parents aged 39 (mother) and 40 years (father), respectively. Physical examination showed facial asymmetry, micrognathia, strabismus, and a large ear; neither cardiac syndrome nor renal abnormalities were observed. The neurological examination revealed poor coordination in gross and fine motor skills. Brain magnetic resonance imaging did not reveal any structural abnormalities in the auditory system.

In the developmental and speech delay evaluation, the scores were $<0.1 \%$ of the scales defining moderate mental retardation in the Korean Bayley Scales of Infant and Toddler DevelopmentII and $<1 \%$ of the scales indicating speech delay Sequenced Language Scale for Infants. However, the Childhood Autism Rating Scale score was 27 (cutoff: 30); thus, she was classified as a non-autistic child.

The cytogenetic examination was carried out on peripheral blood of the patient and her parents. Chromosome harvesting and karyotyping were performed following a standard protocol, phytohemagglutinin-stimulated peripheral blood culture.

The proband's karyotype was defined as 47,XX,+mar in metaphase (Fig. 1A), while the mother and father had normal karyotypes of $46, X X$ and $46, X Y$, respectively. Genomic DNA was ob-
Received: July 12, 2019

Revision received: October 15, 2019

Accepted: November 26, 2019

Corresponding author: Jung Ah Kwon, M.D.

Department of Laboratory Medicine, Korea University College of Medicine,

148 Gurodong-ro, Guro-gu, Seoul 08308, Korea

Tel: +82-2-2626-3243, Fax: +82-2-2626-1465,

E-mail: jakwon83@korea.ac.kr

\section{(c) $(1) \Theta$}

(C) Korean Society for Laboratory Medicine

This is an Open Access article distributed under the terms of the Creative Commons Attribution Non-Commercial License (http://creativecommons.org/licenses/by-nc/4.0) which permits unrestricted non-commercial use, distribution, and reproduction in any medium, provided the original work is properly cited. 
tained from patient's peripheral blood and subjected to array$\mathrm{CGH}$ analysis (Fig. 1B). Molecular characterization of the sSMC identified it as arr[GRCh38] 20p13p11.1(140880_26207158)

x3 (Fig. 1). According to the array-CGH results, the sSMC of our
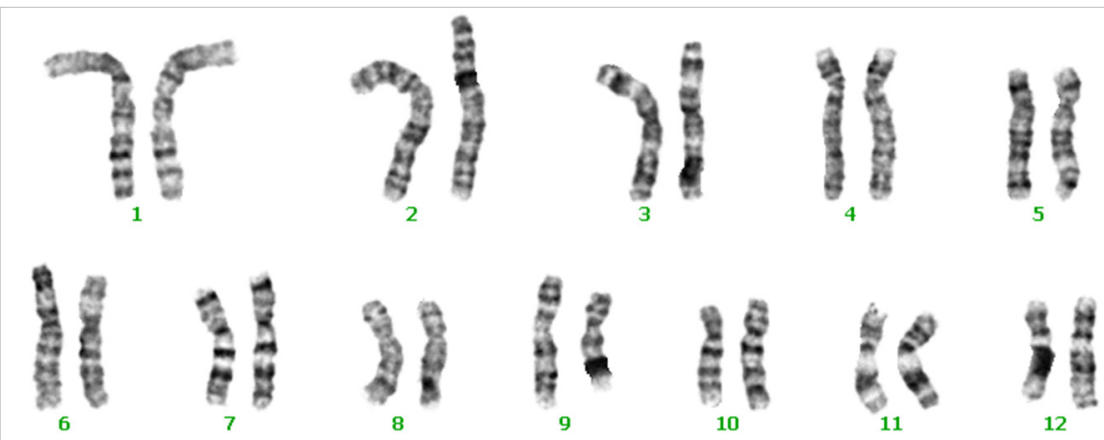

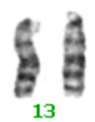
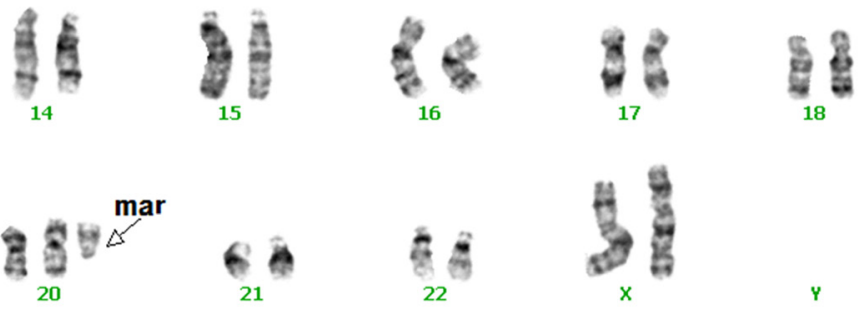

Fig. 1. Chromosome analysis and array CGH. (A) Karyotype of the patient showing the marker chromosome (arrow). (B) Detailed views of the microarray plots for the patient. The horizontal axis shows megabases $(\mathrm{Mb})$ from the chromosome 20 (26.06 Mb duplication), and the vertical axis shows the fold-change in copy number variation (red dot: patient DNA tagged with red fluorescence, green dot: reference control DNA tagged with red fluorescence).

Abbreviation: CGH, comparative genomic hybridization.

A
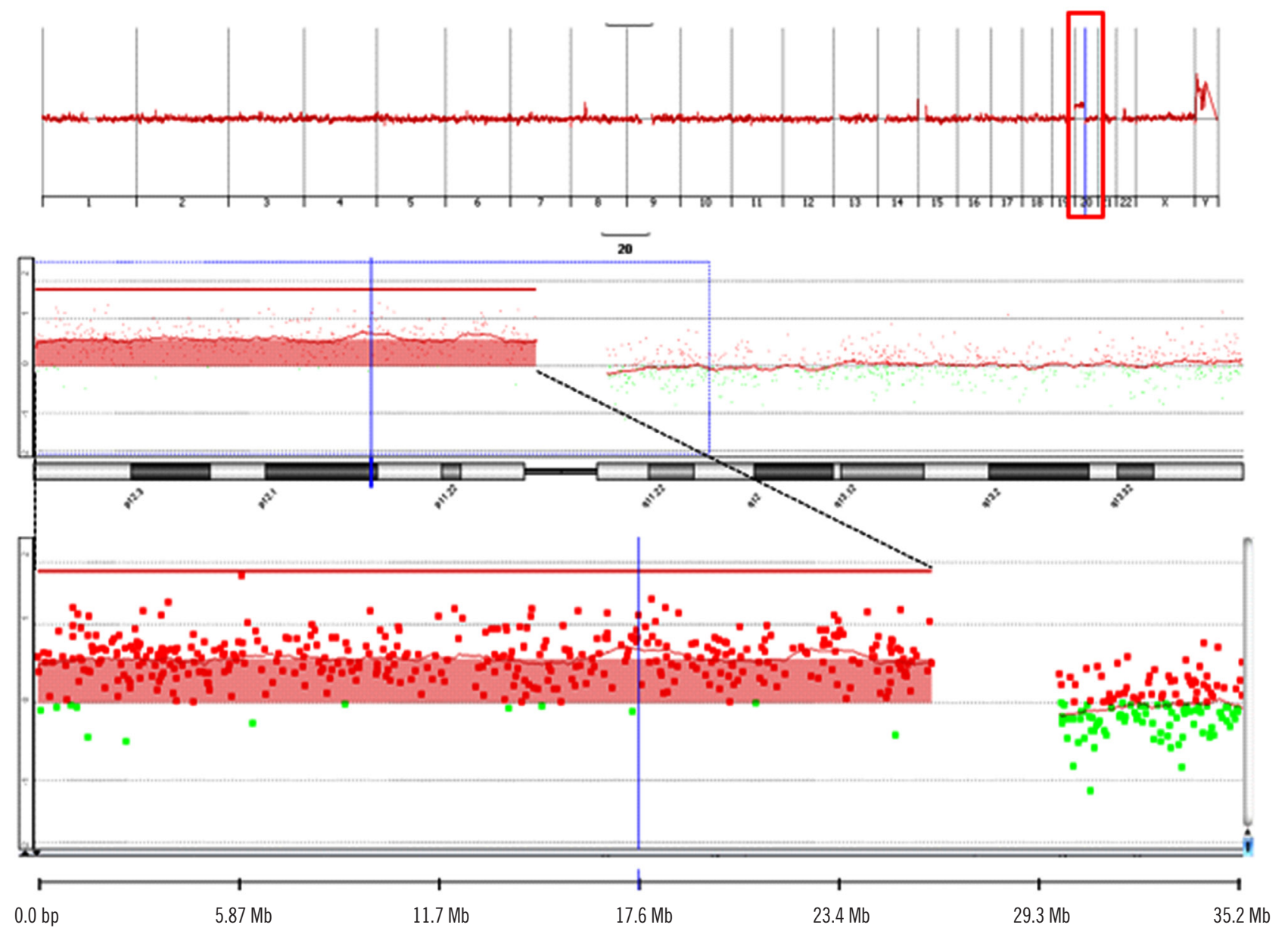


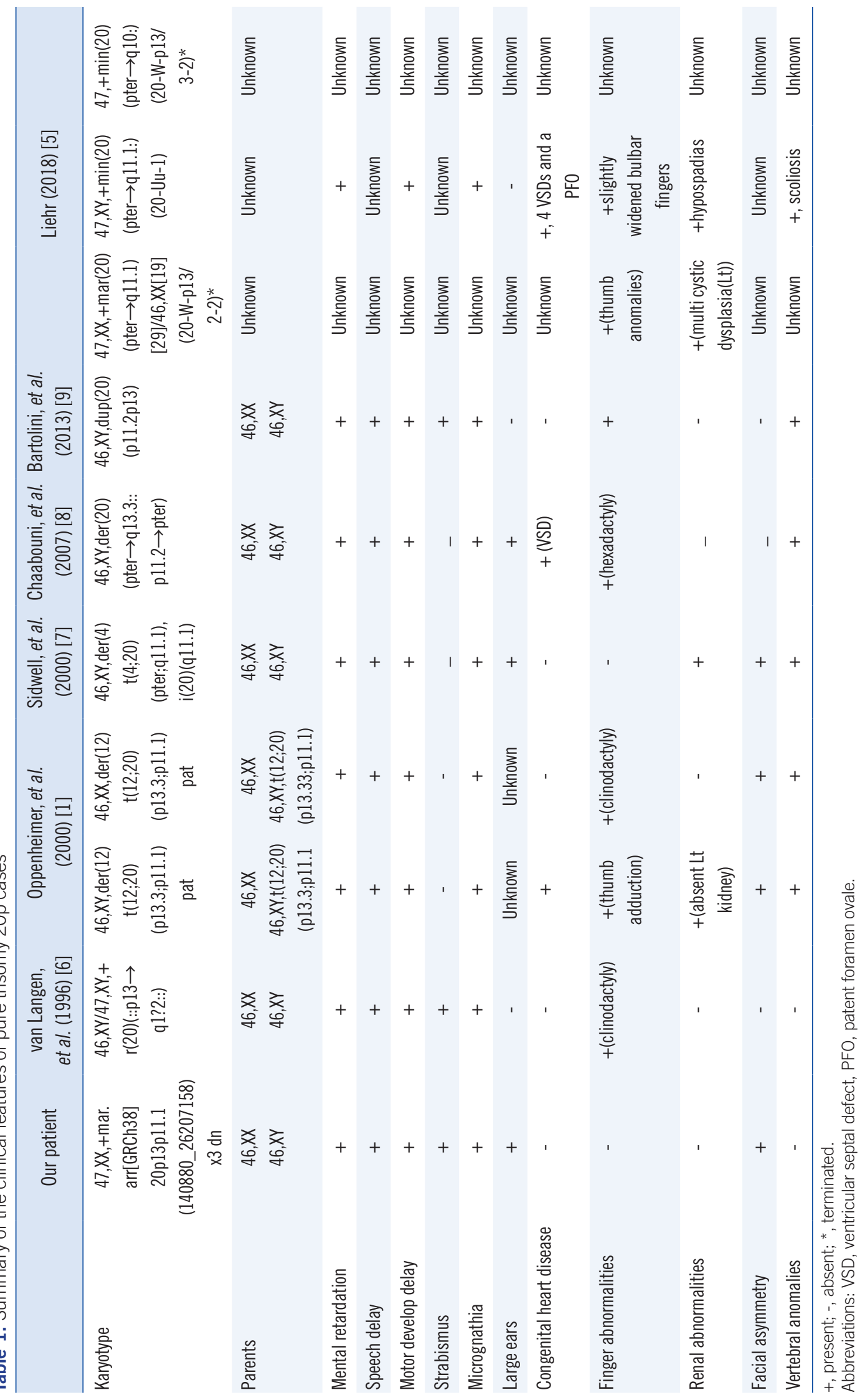


patient included the entire short arm (26.06 Mb) of chromosome 20 , which is not related to the long arm of chromosome 20 or to other chromosomes. In addition, no mosaicism was detected. The effects of the SSMC on phenotype depend on euchromatin size (>1 Mb) and the level of mosaicism (average 68\%) [5].

The clinical findings of the present case were similar to those of previously reported pure trisomy 20p cases (Table 1). The patient reported by Sidwell, et al. [7] grew normally (approximately 10th percentile) and achieved improvement through speech therapy and physiotherapy. Our patient showed no skeletal abnormalities till date and is able to walk on her own. She is evaluated regularly at our clinic and is under careful observation. Some studies have reported that SSMC also increases the risk of uniparental disomy (UPD) $[5,10]$. Therefore, the limitation of our study is that the UPD testing was not performed.

Majority of patients with trisomy 20p syndrome seem to have normal weight at birth and survive through adulthood, which may delay diagnosis similar to that in our patient. Therefore, early detection of trisomy 20p is important in diagnosis and proper genetic counseling. Our case is the first report of a pure trisomy $20 p$ from sSMC in Korea.

\section{AUTHOR CONTRIBUTIONS}

Drafting of the manuscript: JC, JAK. Review of patients' clinical information: BLE. Critical revision of the manuscript: BGP, SYY, JAK. Interpretation of genetic data: MK, JAK.

\section{CONFLICTS OF INTEREST}

None declared.

\section{RESEARCH FUNDING}

None declared.

\section{ORCID}

Jungim Choi

https://orcid.org/0000-0001-9598-453X

Soo-Young Yoon https://orcid.org/0000-0002-2302-3825

Borae G. Park

Baik-lin Eun

Myungshin Kim

Jung Ah Kwon https://orcid.org/0000-0001-9710-9253 https://orcid.org/0000-0001-8735-292X https://orcid.org/0000-0001-8632-0168 https://orcid.org/0000-0001-5321-7279

\section{REFERENCES}

1. Oppenheimer S, Dignan P, Soukup S. Partial trisomy 20p: familial occurrence. Am J Med Genet 2000;95:316-9.

2. Centerwall $W$ and Francke U. Familial trisomy 20p five cases and two carriers in three generations a review. Ann Genet 1977;20:77-83.

3. Grammatico P, Cupilari F, Di Rosa C, Falcolini M, Del Porto G. 20 p duplication as a result of parental translocation: familial case report and a contribution to the clinical delineation of the syndrome. Clin Genet 1992; 41:285-9.

4. Kang JE, Park MY, Cheon CK, Lee HD, Hwang SH, Yi J. A case of partial trisomy 20p resulting from meiotic recombination of a maternal pericentric inversion. Ann Lab Med 2012;32:91-4.

5. Liehr T. Small supernumerary marker chromosomes. http://ssmc-tl.com/ sSMC.html. (Updated on Nov 2018).

6. van Langen IM, Otter MA, Aronson DC, Overweg-Plandsoen WC, Hennekam RC, Leschot NJ, et al. Supernumerary ring chromosome 20 characterized by fluorescence in situ hybridization. Clin Genet 1996;49:4953.

7. Sidwell R, Pinson M, Gibbons B, Byatt S, Svennevik E, Hastings RJ, et al. Pure trisomy 20p resulting from isochromosome formation and whole arm translocation. J Med Genet 2000;37:454-8.

8. Chaabouni M, Turleau C, Karboul L, Jemaa LB, Maazoul F, Attié-Bitach T, et al. De novo trisomy 20p of paternal origin. Am J Med Genet A 2007; 143A:1100-3.

9. Bartolini L, Sartori S, Lenzini E, Rigon C, Cainelli E, Agrati C, et al. De novo trisomy 20p characterized by array comparative genomic hybridization: report of a novel case and review of the literature. Gene 2013; 524:368-72

10. Izumi K, Kubota N, Arakawa M, Takayama M, Harada Y, Nakamura T, et al. Dissecting the phenotype of supernumerary marker chromosome 20 in a patient with syndromic pierre robin sequence: combinatorial effect of gene dosage and uniparental disomy. Am J Med Genet A 2015; 167:1289-93. 